\title{
Development of mass media resources to improve the ability of parents of primary school children in Uganda to assess the trustworthiness of claims about the effects of treatments: a human-centred design approach
}

Daniel Semakula ${ }^{1,2}$, Allen Nsangi ${ }^{1,2}$, Matt Oxman ${ }^{3}$, Sarah Ellen Rosenbaum ${ }^{3}$, Andrew David Oxman ${ }^{2,3^{*}}$, Astrid Austvoll-Dahlgren ${ }^{3}$, Claire Glenton ${ }^{3}$, Simon Lewin ${ }^{3,4}$, Margaret Kaseje ${ }^{5}$, Angela Morelli, Atle Fretheim ${ }^{2,3}$ and Nelson Kaulukusi Sewankambo ${ }^{1}$

\begin{abstract}
Background: Claims about what we need to do to improve our health are everywhere. Most interventions simply tell people what to do, and do not empower them to critically assess health information. Our objective was to design mass media resources to enable the public to critically appraise the trustworthiness of claims about the benefits and harms of treatments and make informed health choices.

Methods: Research was conducted between 2013 and 2016 across multiple iterative phases. Participants included researchers, journalists, parents, other members of the public. First, we developed a list of 32 key concepts that people need to understand to be able to assess the trustworthiness of claims about treatment effects. Next, we used a human-centred design approach, to generate ideas for resources for teaching the key concepts, and developed and user-tested prototypes through qualitative interviews. We addressed identified problems and repeated this process until we had a product that was deemed relevant and desirable by our target audience, and feasible to implement.

Results: We generated over 160 ideas, mostly radio-based. After prototyping some of these, we found that a podcast produced collaboratively by health researchers and journalists was the most promising approach. We developed eight episodes of the Informed Health Choices podcast, a song on critical thinking about treatments and a reminder checklist. Early versions of the podcast were reportedly too long, boring and confusing. We shortened the episodes, included one key concept per episode, and changed to story-telling with skits. The final version of the podcast was found to be useful, understandable, credible and desirable.
\end{abstract}

Conclusion: We found many problems with various prototypes of mass media resources. Using a human-centred design approach, we overcame those problems. We have developed a guide to help others prepare similar podcasts.

Keywords: Human-centred design, Intervention-design, User testing, User experience, Mass media, Critical thinking, Critical appraisal, Health education

\footnotetext{
* Correspondence: oxman@online.no

2University of Oslo, Oslo, Norway

${ }^{3}$ Centre for Informed Health Choices, Norwegian Institute of Public Health,

Postboks 222 Skøyen, 0213 Oslo, Norway

Full list of author information is available at the end of the article
}

(c) The Author(s). 2019 Open Access This article is distributed under the terms of the Creative Commons Attribution 4.0 International License (http://creativecommons.org/licenses/by/4.0/), which permits unrestricted use, distribution, and reproduction in any medium, provided you give appropriate credit to the original author(s) and the source, provide a link to the Creative Commons license, and indicate if changes were made. The Creative Commons Public Domain Dedication waiver (http://creativecommons.org/publicdomain/zero/1.0/) applies to the data made available in this article, unless otherwise stated. 


\section{Background}

We encounter claims about the effects of treatments (any action intended to improve health) all the time. This includes claims about the effects of drugs, surgery and other types of "modern medicine"; claims about lifestyle changes, such as changes to what you eat or how you exercise; claims about herbal remedies and other types of "traditional" or "alternative medicine"; claims about public health and environmental interventions; and claims about changes in how healthcare is delivered, financed and governed. New treatment claims are made every day in the mass media.

While some claims are trustworthy, many are not, and the trustworthiness of claims found in the mass media frequently is not adequately assessed [1-11]. This can affect health behaviours and healthcare use [12-14]. To make informed choices, people need to be able to assess the trustworthiness of treatment claims. Untrustworthy treatment claims and misinformed decisions about treatments result in wasted resources and unnecessary suffering [15-19]. This is a universal problem, but the consequences are likely to be greater in settings where resources are scarce [20-24].

The Informed Health Choices (IHC) project was established with the aim of developing learningresources to improve people's ability to assess the trustworthiness of claims about treatment effects and enable them to make informed decisions about treatments [25]. Our initial focus was on low-income countries where disparities in access to information, education and care are likely to be larger and the consequences of making poorly informed health choices are likely to be greater [26-29]. In the first phase of this work, we developed a list of 32 key concepts that people need to understand in order to be able to assess treatment claims and make informed decisions [30]. The key concepts can help people to recognise treatment claims that have an unreliable basis, understand whether comparisons of treatments are fair and reliable and make informed decisions about treatments. Journalists in Uganda judged the concepts to be relevant to journalists and their audiences and possible for them to learn [31].

The IHC key concepts served as a framework for developing two sets of learning-resources: one for primary schools and one for the mass media in Uganda [32]. The development of the primary school resources is described elsewhere [33], and other potential applications of the key concepts are described in another report [32]. This article describes the development of mass media resources designed to enable people to understand and apply the IHC key concepts to assess the trustworthiness of claims about treatment effects and make informed health choices.

\section{Methods}

We used design thinking methods. Design thinking espouses five major steps: (1) empathising to define the problem, (2) defining the problem, (3) ideation, (4) prototyping (experimenting on potential solutions) and (5) testing [34]. We overlaid design thinking with a human-centred design approach [35-38]. This approach is characterised by multiple iterative cycles of development. For simplicity, we have summarised that process into four steps: (1) idea generation, (2) prototyping, (3) user testing and (4) analysis and incorporation of findings (Fig. 1).

\section{Setting}

This project was implemented in Central Uganda. The majority (over $70 \%$ ) of people live in rural areas only slightly more than $30 \%$ have attained at least secondary school education [39].

\section{Participants}

Different participants were involved at different stages as described in Table 1, which presents a chronological descriptive summary of each phase and who participated. Throughout the project, we established and maintained contact with a national advisory panel consisting of officials from three government ministries (health, education and one concerned with children, labour, gender and social development). We also established and maintained contact with a network of teachers, and journalists, editors of Ugandan media enterprises and communication specialists, whose role was to advise on strategies for successful implementation of the project.

In an early phase of the project, our principal target audiences were "mass media intermediaries"-journalists

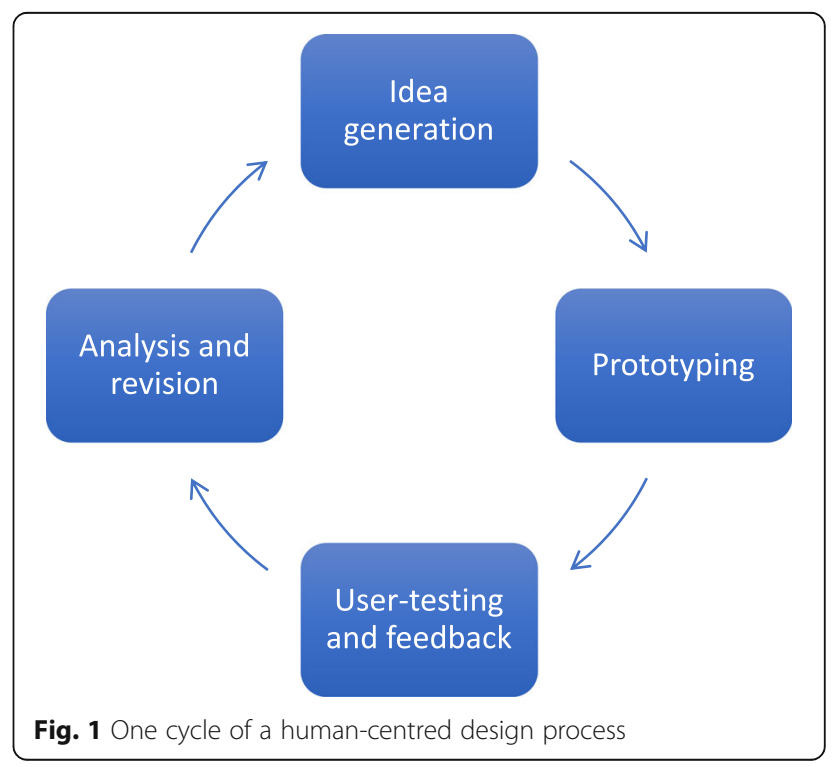


Table 1 Overview of the methods, key activities and participants in each phase of the development process

\begin{tabular}{|c|c|}
\hline Method type/date & Participants \\
\hline \multicolumn{2}{|c|}{ Idea generation and exploratory prototypes } \\
\hline $\begin{array}{l}\text { Review of existing } \\
\text { resources } \\
\text { February } 2013 \text { to } \\
\text { September } 2014\end{array}$ & $\begin{array}{l}\text { The research team (AA, AM, AN, } \\
A O, C G, D S, S L, S R)\end{array}$ \\
\hline $\begin{array}{l}\text { Idea generation } \\
\text { workshop } \\
\text { (participatory } \\
\text { collaboration) } \\
\text { February } 2013\end{array}$ & $\begin{array}{l}\text { Researchers, teachers and } \\
\text { journalists from Indonesia, Nepal, } \\
\text { Norway, Uganda and the UK }\end{array}$ \\
\hline $\begin{array}{l}\text { Prioritisation of } \\
\text { key concepts } \\
\text { (participatory } \\
\text { collaboration) } \\
\text { August } 2013\end{array}$ & $\begin{array}{l}\text { The journalists' network in } \\
\text { Uganda (25 journalists) [17] }\end{array}$ \\
\hline $\begin{array}{l}\text { Prototyping } \\
\text { workshop (facilitation } \\
\text { and non-participatory } \\
\text { observation) } \\
\text { September } 2013\end{array}$ & $\begin{array}{l}\text { The journalists' network in } \\
\text { Uganda, ( } 25 \text { journalists) }\end{array}$ \\
\hline $\begin{array}{l}\text { Idea generation } \\
\text { meetings and } \\
\text { prototyping } \\
\text { (participatory } \\
\text { collaboration) } \\
\text { October } 2013 \text { to } \\
\text { October } 2014\end{array}$ & $\begin{array}{l}\text { The research team (AA, AM, } \\
A N, A O, C G, D S, L N, M K, M O \text {, } \\
N S, S L, S R)\end{array}$ \\
\hline $\begin{array}{l}\text { Focus group } \\
\text { feedback (focus } \\
\text { group discussion and } \\
\text { semi-structured } \\
\text { interviews) } \\
\text { October } 2014\end{array}$ & $\begin{array}{l}\text { Four media editors, a journalist } \\
\text { and a health communication } \\
\text { specialist. Four random members } \\
\text { of the public }\end{array}$ \\
\hline $\begin{array}{l}\text { Focus group } \\
\text { feedback (focus } \\
\text { group discussion and } \\
\text { semi-structured } \\
\text { interviews) } \\
\text { October } 2014\end{array}$ & $\begin{array}{l}\text { Four media editors, a journalist } \\
\text { and a communication specialist. } \\
\text { Four random members of the } \\
\text { nonacademic public. }\end{array}$ \\
\hline $\begin{array}{l}\text { Semi-structured } \\
\text { interviews } \\
\text { October } 2014\end{array}$ & $\begin{array}{l}\text { Four members of the } \\
\text { general public }\end{array}$ \\
\hline
\end{tabular}
Description of key activities

We searched for and reviewed existing mass media resources that teach the key concepts.

At the 3-day kick-off meeting for the project, the research team together with invited teachers and journalists (18 people) discussed which concepts to focus on and brainstormed about potential resources.

At a 3-day workshop, the journalists assessed the relevance of a list of 32 key concepts to journalists and their audiences.

This was a full-day workshop at which journalists brainstormed and created prototypes.

We had a series of meetings during which we brainstormed. One idea was a service that would provide structured press releases, including application of the key concepts to a treatment claim. We prototyped one press release. Another was a wire service that would produce short stories that would explain key concepts to readers and

listeners in the context of news about a specific treatment claim. We prototyped two examples of stories produced by such a news service one as a print story and one as a radio programme.

Structured press releases: The participants read the press release, and then provided feedback.

News service: The participants read or listened to each of the stories and then provided feedback. Following this, we interviewed three of the participants of the focus group discussion and each of the four members of the public

The participants listened to and read the prototypes of the messages and provided feedback about the news service. Any problems identified were noted and followed up.

We reviewed the feedback on the news service prototype and generated ideas to address the problems that we identified.

We outlined plans for a series of what we initially thought of as a radio programme and prepared prototypes of two versions of the first episode; one using an interview format and one using a story format.

Two versions of prototype 1 were tested in sequence. First, the participants listened to the first version of the prototype (1a) and provided early feedback. We then user-tested an alternative prototype (1b) of the same contents as the first with a 
Table 1 Overview of the methods, key activities and participants in each phase of the development process (Continued)

\begin{tabular}{|c|c|}
\hline Method type/date & Participants \\
\hline $\begin{array}{l}\text { V1 Analysis and idea } \\
\text { generation for V2 } \\
\text { May } 2015\end{array}$ & $\begin{array}{l}\text { The research team (AA, AM, } \\
A O, C G, D S, M K, M O, N S, S L, S R)\end{array}$ \\
\hline \multicolumn{2}{|l|}{ Version 2. The IHC podcast (v2) } \\
\hline $\begin{array}{l}\text { Interviews with parents to identify } \\
\text { relevant claims } \\
\text { (semi-structured } \\
\text { interviews) } \\
\text { March-April } 2015\end{array}$ & 30 parents \\
\hline $\begin{array}{l}\text { V2 Development } \\
\text { of the second } \\
\text { complete prototype } \\
\text { June to August } 2015\end{array}$ & $\begin{array}{l}\text { The research team (AA, AM, AN, } \\
\mathrm{AO}, \mathrm{CG}, \mathrm{DS}, \mathrm{MK}, \mathrm{MO}, \mathrm{NS}, \mathrm{SL}, \mathrm{SR}) \\
\text { Radio producer, actors, journalist } \\
\text { and parents of primary school } \\
\text { children }\end{array}$ \\
\hline $\begin{array}{l}\text { V2 User testing and } \\
\text { piloting in Uganda } \\
\text { (semi-structured } \\
\text { interviews) } \\
\text { September to } \\
\text { December } 2015\end{array}$ & $\begin{array}{l}28 \text { parents and } 7 \text { research } \\
\text { assistants }\end{array}$ \\
\hline $\begin{array}{l}\text { V2 Analysis and idea } \\
\text { generation for V3 } \\
\text { December } 2015 \\
\text { to January } 2016\end{array}$ & $\begin{array}{l}\text { The research team (AA, AM, AN, } \\
A O, C G, D S, L N, M K, M M, M O \text {, } \\
N S, S L, S R \text { ) } \\
\text { Radio producer, journalists } \\
\text { and parents. }\end{array}$ \\
\hline
\end{tabular}

bey activities

story-based theme. Prototype $1 \mathrm{~b}$ was partly based on early feedback from the testing of prototype 1a.

We analysed the feedback and discussed findings from the user testing and feedback

on the first version of the $\mathrm{IHC}$ podcast and generated ideas to address the problems that were identified.

We interviewed parents to identify health conditions and treatments that were relevant to them.

We prepared a series of nine episodes targeted at the parents of primary school

children in Uganda. MO prepared a script for each episode, which was edited by DS and $\mathrm{AO}$, and other team members provided feedback. A professional radio producer and actors produced the episodes.

28 parents listened to the podcast. We interviewed them after they listened to each episode. With the help of the parents and research assistants, we also piloted a method for delivering the podcast to the parents in areas where they live and work, collecting feedback on the method and technologies used.

We entered the findings into a Google spreadsheet. For each finding, AN, AO, DS, MM,

$\mathrm{MO}$ and SR coded its importance (very important, important or less important); whether it was a problem, an idea or positive feedback; and whether it applied to the entire podcast, a specific episode or was a repeat of a previous finding. The findings

were summarised for the research team and the major findings and plans for the third

version, and the community trial were discussed and agreed.

Version 3. The final IHC podcast (v3)

V3 Development of the final podcast January to March 2016

The research team $(A A, A M, A N$, $A O, C G, D S, L N, M K, M M, M O$,

$N S, S L, S R)$

Radio producer, actors, musicians, parents of primary school children, other members of the general public

The research team $(A A, A M$, AN, AO, CG, DS, SL, SR)

Review of existing resources February 2013 to September 2014

Idea generation workshop (participatory collaboration)

February 2013

Prioritisation of

key concepts

(participatory collaboration)

August 2013

Researchers, teachers and journalists from Indonesia, Nepal, Norway, Uganda and the UK

The journalists' network in Uganda (25 journalists) [17]
MO prepared new scripts, which were edited by DS and AO. Other team members

provided feedback. DS translated scripts to Luganda. DS, AN, AO prepared the lyrics to

the theme song. Other members provided feedback. A professional musician was

commissioned to edit the lyrics and produce the song. A professional radio producer

and actors produced the episodes. DS, AN, AO and MO reviewed the produced

episodes and suggested edits to the production.

We searched for and reviewed existing mass media resources that teach the

key concepts.

At the 3-day kick-off meeting for the project, the research team together with invited teachers and journalists (18 people) discussed which concepts to focus on and brain stormed about potential resources.
At a 3-day workshop, the journalists assessed the relevance of a list of 32 key concepts

to journalists and their audiences. 
Table 1 Overview of the methods, key activities and participants in each phase of the development process (Continued)

\begin{tabular}{ll}
\hline Method type/date & Participants \\
\hline Prototyping & The journalists' network in \\
workshop (facilitation & Uganda, (25 journalists) \\
and non-participatory & \\
observation) & \\
September 2013 & \\
Idea generation & The research team (AA, AM, \\
meetings and & AN, AO, CG, DS, LN, MK, MO \\
prototyping & NS, SL, SR) \\
(participatory & \\
collaboration) & \\
October 2013 & \\
to October 2014 &
\end{tabular}

\author{
Focus group \\ feedback (focus \\ group discussion and \\ semi-structured \\ interviews) \\ October 2014

\section{Focus group \\ feedback (focus \\ semi-structured \\ interviews) \\ Semi-structured \\ interviews} \\ group discussion and \\ October 2014
}

October 2014

\author{
Analysis of findings \\ and idea generation \\ October 2014
}

Version 1. The Health Choices

(radio) programme (v1)

V1 Development of

a prototype

October 2014 to April 2015

\author{
V1 User testing \\ in Uganda \\ (semi-structured \\ interviews) \\ April 2015
}

\section{V1 Analysis and idea generation for $\mathrm{V} 2$}

May 2015

Version 2. The IHC podcast (v2)
Four media editors, a journalist and a health communication specialist. Four random members of the public

Four media editors, a journalist and a communication specialist. Four random members of the nonacademic public.

Four members of the general public

The research team $(A A, A M$, $A N, A O, C G, D S, L N, M K, M O$, NS, SL, SR)

The research team (AA, $A M$, AN, AO, CG, DS, MO, SL, SR)

Two health journalists and four other members of the nonacademic public

The research team (AA, AM, $A O, C G, D S, M K, M O, N S, S L, S R$ ) Description of key activities

This was a full-day workshop at which journalists

brainstormed and created prototypes.

We had a series of meetings during which we

brainstormed. One idea was a service

that would provide structured press releases,

including application of the key concepts

to a treatment claim. We prototyped one press

release. Another was a wire service

that would produce short stories that would explain

key concepts to readers and

listeners in the context of news about a specific treatment claim. We prototyped two

examples of stories produced by such a news service;

one as a print story and one as

a radio programme.

Structured press releases: The participants read the press release, and then provided feedback.

News service: The participants read or listened to each of the stories and then provided feedback. Following this, we interviewed three of the participants of the

focus group discussion and each of the four members of the public

The participants listened to and read the prototypes of the messages and provided feedback about the news service. Any problems identified were noted and followed up.

We reviewed the feedback on the news service prototype and generated ideas to address the problems that we identified.

We outlined plans for a series of what we initially thought of as a radio programme

and prepared prototypes of two versions of the first episode; one using an interview format and one using a story format.

Two versions of prototype 1 were tested in sequence. First, the participants listened to the first version of the prototype (1a) and provided early feedback. We then

user-tested an alternative prototype (1b) of the same contents as the first with a

story-based theme. Prototype $1 \mathrm{~b}$ was partly based on early feedback from the testing

of prototype 1 a.

We analysed the feedback and discussed findings from the user testing and feedback on the first version of the $\mathrm{IHC}$ podcast and generated ideas to address the problems that were identified.

We interviewed parents to identify health conditions and treatments that were relevant to them.
30 parents

Interviews with
parents to identify
relevant claims
(semi-structured
interviews)
March-April 2015


Table 1 Overview of the methods, key activities and participants in each phase of the development process (Continued)

\begin{tabular}{|c|c|c|}
\hline Method type/date & Participants & Description of key activities \\
\hline $\begin{array}{l}\text { V2 Development of } \\
\text { the second complete } \\
\text { prototype } \\
\text { June to August } 2015\end{array}$ & $\begin{array}{l}\text { The research team (AA, AM, AN, } \\
A O, C G, D S, M K, M O, N S, S L, S R) \\
\text { Radio producer, actors, journalists } \\
\text { and parents of primary school } \\
\text { children }\end{array}$ & $\begin{array}{l}\text { We prepared a series of nine episodes targeted } \\
\text { at the parents of primary school } \\
\text { children in Uganda. MO prepared a script for } \\
\text { each episode, which was edited by DS } \\
\text { and AO and other team members provided feedback. } \\
\text { A professional radio producer } \\
\text { and actors produced the episodes. }\end{array}$ \\
\hline $\begin{array}{l}\text { V2 User testing and } \\
\text { piloting in Uganda } \\
\text { (semi-structured } \\
\text { interviews) } \\
\text { September to } \\
\text { December } 2015\end{array}$ & $\begin{array}{l}28 \text { parents and } 7 \text { research } \\
\text { assistants }\end{array}$ & $\begin{array}{l}28 \text { parents listened to the podcast. We interviewed } \\
\text { them after they listened to each } \\
\text { episode. With the help of the parents and research } \\
\text { assistants, we also piloted a } \\
\text { method for delivering the podcast to the parents in } \\
\text { areas where they live and work, } \\
\text { collecting feedback on the method and technologies used. }\end{array}$ \\
\hline $\begin{array}{l}\text { V2 Analysis and idea } \\
\text { generation for V3 } \\
\text { December } 2015 \text { to } \\
\text { January } 2016\end{array}$ & $\begin{array}{l}\text { The research team (AA, AM, AN, } \\
A O, C G, D S, L N, M K, M M, M O, N S \text {, } \\
S L, S R \text { ) } \\
\text { Radio producer, journalists and } \\
\text { parents. }\end{array}$ & $\begin{array}{l}\text { We entered the findings into a Google spreadsheet. For } \\
\text { each finding, DS, AN, AO, MM, } \\
\text { MO and SR coded its importance (very important, important } \\
\text { or less important); } \\
\text { whether it was a problem, an idea or positive feedback; } \\
\text { and whether it applied to the } \\
\text { entire podcast, a specific episode or was a repeat of a } \\
\text { previous finding. The findings } \\
\text { were summarised for the research team and the major } \\
\text { findings and plans for the third } \\
\text { version, and the community trial were discussed and agreed. }\end{array}$ \\
\hline \multicolumn{3}{|c|}{ Version 3. The final IHC podcast (v3) } \\
\hline $\begin{array}{l}\text { V3 Development of } \\
\text { the final podcast } \\
\text { January to March } 2016\end{array}$ & $\begin{array}{l}\text { The research team (AA, AM, AN, } \\
\text { AO, CG, DS, LN, MK, MM, MO, NS, } \\
\text { SL, SR) } \\
\text { Radio producer, actors, musicians, } \\
\text { parents of primary school children, } \\
\text { other members of the } \\
\text { general public }\end{array}$ & $\begin{array}{l}\text { MO prepared new scripts, which were edited by DS and } \\
\text { AO. Other team members } \\
\text { provided feedback. DS translated scripts to Luganda. DS, } \\
\text { AN, AO prepared the lyrics to } \\
\text { the theme song. Other members provided feedback. A } \\
\text { professional musician was } \\
\text { commissioned to edit the lyrics and produce the song. } \\
\text { A professional radio producer } \\
\text { and actors produced the episodes. DS, AN, AO and MO } \\
\text { reviewed the produced episodes and suggested edits to the production. }\end{array}$ \\
\hline
\end{tabular}

and editorial news teams. Aiming to reach a broader public through intermediaries, we explored ideas about resources we might develop to support their work, so they could report health stories about treatment claims more critically and informatively. We established a network of 25 Uganda journalists with interest and experience in health reporting, to generate resource ideas and provide feedback on prototypes. These were conveniently selected based on their availability and interest in health reporting and in the project. We recruited them by contacting leaders of three major health journalists' professional organisations in Uganda (Uganda Science Journalists' Association, Health Journalists Network of Uganda and Uganda Health Communication Alliance) and the national professional organisation for journalists (Uganda Journalists' Association). We asked them to avail us with names of journalists and media practitioners involved in health-related reporting. We describe this process in greater detail in another report [31]. We also recruited a group of editors from Uganda media houses, based on recommendations from the journalists in our network and others working in mass media organisations.

In subsequent phases, our focus shifted to creating resources that would target mass media audiences directly instead of through intermediaries. In order to narrow our focus further and to complement the set of learningresources we were developing for children in primary schools, we defined our target audience as the parents of primary school children in Uganda We recruited parents with children in year five of primary school who, like the journalist network, participated by generating ideas and providing feedback on prototypes and the subsequent versions of the resources.

The research team participated in idea generation, data analysis and prototype refinement. It included researchers with backgrounds in health systems research, journalism, public health, medicine, social sciences and information design. We engaged professional radio presenters, actors, musicians and music producers to help develop the final versions of the mass media resources.

\section{Procedures}

The development work entailed five phases: (1) review of existing resources and prioritisation of key concepts, (2) idea generation and exploratory prototypes, (3) version 1 of what became the IHC podcast, (4) version 2 of 
the IHC podcast and (5) version 3 of the IHC podcast (Fig. 2).

\section{Review of existing resources and prioritisation of key concepts}

We searched for and reviewed existing mass media and other resources designed to improve public understanding of health information and their ability to assess the trustworthiness of information about claims of the effects of treatments in the mass media. We searched relevant databases for published literature and contacted researchers in relevant fields [40, 41]. We held workshops with key stakeholders such as journalists to set priorities for key concepts for which we should develop resources [31].

\section{Idea generation}

To generate new ideas for resources to be developed, we conducted brainstorming sessions both within our research team and with the journalists network [42]. In addition, we conducted a 1-day workshop with journalists in which we explained to them the idea and asked for their contributions (Additional file 1).

\section{Prototyping}

We collected all of the ideas that we generated in a spreadsheet from which we selected ideas for prototyping (Additional file 1). The criteria used to decide which ideas to develop resources for is summarised in Table 2 below.

Working with information designers and journalists, we converted written descriptions of ideas into prototypes.
For example, for ideas about print-based news stories, we wrote actual news stories based on claims about treatment effects in the media, while for ideas of radio programmes we produced and recorded a version of a radio programme. These prototypes were then shared with potential users, journalists and members of our research team for user testing and feedback.

\section{User testing and feedback}

We varyingly used a combination of concurrent and retrospective think aloud and retrospective probing methods of formative usability testing to monitor people's understanding of the content of our products along the development pathway. In the concurrent think aloud method, testers are encouraged to verbalise their thoughts as they test a service while in retrospective think aloud method, they recall their thoughts and can relay them in post-use interviews and discussions [43]. For instance, to collect feedback about a news service idea, we presented an example of a news story that might come from such a service to a group including editors, a journalist and a communication specialist. As they read it, they made notes on the articles, marking areas where they had comments and sometimes voicing those out in real time. In addition, we used prompts to elicit discussion and feedback about the specific example as well as the news service concept itself and took notes. In addition to the focus group discussion, we interviewed individual participants using a semi-structured interview form, recorded the interviews and took notes.

In the later phases when we had created prototypes of the podcast, we carried out user testing with people in our target audience. User testing is a process of

\begin{tabular}{|c|c|c|c|c|}
\hline & 2013 & \multicolumn{2}{|l|}{2015} & 2016 \\
\hline & \multicolumn{4}{|l|}{ Prioritising Key Concepts } \\
\hline & \multicolumn{2}{|l|}{32 Key Concepts identified (Described in detail elsewhere) } & \multicolumn{2}{|c|}{ Nine Key Concepts used in Version 3} \\
\hline & & & & \\
\hline \multirow{3}{*}{ 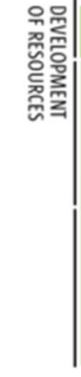 } & Review, idea generation and early prototypes & \multirow{2}{*}{$\begin{array}{l}\text { Version } 1 . \\
\text { The Health } \\
\text { Choices } \\
\text { (radio) } \\
\text { Program }\end{array}$} & \multirow{2}{*}{$\begin{array}{l}\text { Version } 2 . \\
\text { The IHC } \\
\text { podcast }\end{array}$} & \multirow{2}{*}{$\begin{array}{l}\text { Version } 3 \\
\text { The final } \\
\text { IHC } \\
\text { podcast }\end{array}$} \\
\hline & \multirow[t]{2}{*}{$\begin{array}{l}\text { Review of existing resources } \\
\text { Meetings, discussions, workshops, focus group, interviews, } \\
\text { scripting and testing of several early ideas and prototypes }\end{array}$} & & & \\
\hline & & $\begin{array}{l}\text { Developming } \\
\text { partial } \\
\text { prototype, } \\
\text { user-testing }\end{array}$ & $\begin{array}{l}\text { Developing } \\
\text { and piloting } \\
\text { complete } \\
\text { prototype, } \\
\text { user-testing }\end{array}$ & $\begin{array}{l}\text { Finalising } \\
\text { resources }\end{array}$ \\
\hline$\exists$ & $\begin{array}{l}\text { IHC Primary school learning resources: } \\
\text { Development, trial and process evaluation } \\
\text { (Described elsewhere) }\end{array}$ & & & \\
\hline
\end{tabular}

Fig. 2 Development flow chart for the IHC mass media resource. This is a summary of the development process as it unfolded across the timescale of the project 
Table 2 Criteria for deciding on prototypes to develop

\begin{tabular}{ll}
\hline Criterion & Description \\
$\begin{array}{l}\text { Contextual } \\
\text { appropriateness }\end{array}$ & $\begin{array}{l}\text { The idea should align and be seen to align with the cultural, political norms and expectations } \\
\text { in the context where the intervention is to be developed }\end{array}$ \\
Feasibility & $\begin{array}{l}\text { The ideas can potentially be developed easily and practically with resources that are readily } \\
\text { available in the context in which it is to be developed. } \\
\text { Developing the idea should have a reasonable cost, given the available budget and the } \\
\text { context in which the resources would be developed. } \\
\text { Resources developed using the idea could be used or changed in different ways, e.g. by } \\
\text { inserting or removing parts without causing a lot of problems. } \\
\text { Replicability } \\
\text { It should be possible to replicate the development of the resources without losing important } \\
\text { attributes and information }\end{array}$ \\
Transferability & $\begin{array}{l}\text { To the extent possible, the resources or parts of the resources developed from the idea } \\
\text { should be able to be used in other contexts without much difficulty. } \\
\text { Using the resources developed from the idea should depend on having other resources, } \\
\text { e.g. regular support from health workers or teachers. } \\
\text { It should be possible to use the resources on a wider scale }\end{array}$ \\
\hline
\end{tabular}

formative evaluation of a product or service that involves observing a person using a product or service and obtaining feedback during or shortly after they interact with it $[35,36]$.

To assess changes in user experiences along the development pathway, we interviewed user-test participants serially at different stages of the design process. This allowed us to monitor trends in perceptions about the resources in development. We monitored for changes in perceptions regarding the relevance, value, usefulness and other facets of the user-experiences honeycomb framework. We were able to tell when and how perspectives changed with every new prototype and version of the final resources.

We entered the feedback both from user-test participants and from members of the research team into Google spreadsheets. At least two researchers from the IHC team working independently coded each observation for each version of the IHC podcast based on the importance of the finding and its implications for changes to the podcast. The coding was combined in a single spreadsheet, discussed by the coders and consensus was reached (Table 3). Based on these findings, we generated a list of problems and suggestions for changes. We discussed major problems and brainstormed solutions to those problems with the rest of the IHC team. After agreeing on the changes that we would make, we created new prototypes to be user-tested and the design cycle continued until we came up with a final product. We used three main criteria to guide when to end the development iterations:

1. Most of the problems of importance identified in previous prototypes have been addressed as evidenced by their absence in subsequent prototypes and more positive feedback on areas where those problems were.

2. Convergence of responses pertaining to understanding of the content

3. No new major problems have been identified in new prototypes as a result of changes made to previous ones.

During the development of the second version of the IHC podcast, we discussed methods for delivering the podcast to our target audience. The feasibility of these methods was assessed in a pilot exercise using the completed episodes of version 2 . The experiences of research assistants and parents were captured using a semi-structured interview form. Findings from this process generated information about the practical requirements for conducting a community-based randomised trial evaluating the effectiveness of the podcast [44] and informed our next steps in the development and delivery of version 3 of the IHC podcast.

\section{Results \\ Participants' characteristics}

Members of the journalists' network included 14 females and 11 males with a median age of 32 years and median years of experience of 5 years. The majority ( 16 out of 25 ) worked with private media enterprises while the rest worked with government (8 out of 25) or governmentprivate media partnerships (1 out of 25). Most (18 out of 25 ) worked in urban areas and had at least tertiary education (23 out of 25).

Parents who participated in the user testing were mainly female (20 out of 28), had a median age of 28 years, had an education level of primary or less (19 out of 28) and were employed in the informal sector running small home-based businesses ( 25 out of 28 ). 
Table 3 Coding of the importance of feedback for the users' experience

\begin{tabular}{ll}
\hline Category & Description \\
\hline Highly important problem & A problem with the resources that must probably be addressed for the resources to be effective \\
$\begin{array}{l}\text { Important problem } \\
\text { Problem }\end{array}$ & A problem with the resources that should probably be addressed for part of the resources to be effective \\
Highly important positive feedback & Positive response that probably should inspire in changes to the resources \\
Important positive feedback & Praise that maybe should inspire changes to the resources \\
Positive feedback & Praise that validates the resources as they are \\
Highly important idea & An idea that probably should inspire changes to the resources \\
Important idea & An idea that maybe should inspire changes to the resources \\
Idea & An idea that probably should not inspire changes to the resources \\
\hline
\end{tabular}

\section{Review of existing resources and prioritisation of key concepts}

We reviewed a total of 415 eligible studies conducted over the last seven decades. We found that only a handful of the interventions and evaluation tools described included the key concepts that we deem important for people to understand in order to be able to critically appraise the trustworthiness of treatment claims. The key concepts that appeared more frequently in interventions were "Treatments may have beneficial and harmful effects", "Comparisons of treatments should be fair", "Like should be compared with like" and "Single studies can be misleading". We identified a number of different evaluation tools, but only four of these included 10 or more key concepts. None covered all the key concepts. These results are reported in detail elsewhere [40]. A priority-setting exercise we conducted early in the project participants found all six groups of the key concepts to be important, applicable and understandable. The full results from this phase are reported elsewhere [31].

\section{Idea generation and exploratory prototypes}

We initially intended to develop tools for journalists to help them write articles and produce media programmes that would enable the public to think more critically and acquire skills to assess the trustworthiness of claims about the effects of treatments. Through brainstorming sessions with the research team and with journalists, we generated many ideas for doing this. These included the following:

- Practical resources, such as structures for reporting claims about treatment effects, visual aids that could be used to present and explain research evidence, glossaries of health research terms and plain language tools

- Training modules for journalists and journalism students on reporting health research and critically assessing and reporting claims about the effects of treatments

- A journalist network and a researcher network to support journalists in reporting claims about treatment effects
Tools such as these might help to address some barriers to improving reports of treatment claims [45], such as difficulties making health research jargon understandable and access to reliable sources of evidence. However, we decided against these ideas because they would not address important underlying barriers that make it difficult for journalists to report more informatively such as commercialism in the media (the need for journalists to sell stories, which can conflict with providing balanced information) and organisational constraints (such as editors that can be an obstacle to preparing more informative reporting of treatment claims). In addition, we thought that, to the extent that we could develop effective tools for journalists, it was unlikely that they would be widely used outside of a small subset of health journalists, further limiting their impact. Input from the journalist network supported the conclusion that developing tools for journalists would have little if any impact in Uganda.

In the prototyping workshop, the journalists agreed that radio was the best way to reach the broadest audience in Uganda. Most of the prototypes they developed were live talk shows, a format that is popular in Uganda involving health experts as panellists and journalists as moderators. The pros and cons for using radio are summarised in Table 4 below.

\section{Shifting from resources targeting mass media intermediaries to those for the general public}

The findings above relating to difficulties associated with developing resources for journalists led us to shift focus from developing resources for supporting media intermediaries to collaborating with them to jointly produce and publish content. We proceeded to develop two prototypes: first, a rapid response service to meet the public's needs for information about assessing the trustworthiness of claims about the effects of treatments, and then a news wire service to produce short stories for publication in the media (Additional file 2). Co-producing and publishing content with journalists was also seen by journalists and 
media intermediaries as a nonviable option. Key findings from the feedback we received on these prototypes are summarised in Table 5 below:

Based on these findings, we began to explore creating a series of pre-recorded audio messages about assessing the trsutworthiness of claims about the effects of treatments. We decided to develop a programme that closely resembled a live interview talk show. We worked with a multidisciplinary team including journalists, professional actors, editors, health professionals, health researchers and members of our target audience to develop ideas, write scripts and produce a series of pre-recorded audio episodes. A pre-recorded radio show was chosen over a live radio show because of the logistical and technical challenges related to producing live radio shows such as consistency in messaging by presenters and the reliance on media-savvy researchers, skilled moderators, among others. The scripts would be about assessing claims about treatment effects, and recordings could be hosted across multiple electronic media platforms. We initially planned on producing this as a radio programme. Some of the contents of the episodes are outlined in Table 6.

\section{Version 1: the Health Choices radio programme}

Because of the problems earlier identified with live radio, we chose to produce a pre-recorded radio programme (Table 7).

User testing of the first prototype indicated that the detailed explanations were valued, the opinions of members of the public provided authenticity to the programme and the health researcher and professor provided credibility to the programme. However, we identified several problems as outlined below:

\section{Problems associated with the first prototype: the health choices radio programme}

- The first episode was too long (15 min) and the explanations were confusing. There was too much information packed into a single episode, which made it difficult to follow.

- Presenting two claims in one episode created confusion about the take-home messages.
- The programme was not interactive; it had long explanations which made it boring.

- The three members of the audience (in the programme) had very strong opinions about the claims, which were wrong and were sustained after listening to the explanations and the evidence. In addition, some of them introduced new claims about treatment effects when giving their opinions about the claims that we were discussing in the episode.

- The pre-recorded interview sounded unnatural when scripted.

\section{Incorporating feedback into the redesign of the programme} Based on the above findings, we decided to modify the format of the programme, to shorten each episode, to only include one claim in each episode and not to include the opinions of people from the target audience but to use a skit to introduce the claim to be discussed. The skit was in the form of a story. We produced a new prototype that was $8 \mathrm{~min}$, removed the long introduction, shortened the explanations and the conclusion and only used one claim. User testing with members of our target audience (adult members of the public) indicated that the shorter version was better than the previous version and that the explanation using an analogy and examples was good.

However, listeners still confused the claim and the main message about applying an IHC key concept to assess the trustworthiness of the claim. They also still found the programme boring, and the introduction too long. We therefore decided to modify the format again and to produce a podcast series instead of a radio programme. This enabled us to more easily define and reach a target audience. It also removed the constraints of the norms and expectations of radio programmes in Uganda and other problems with radio programmes mentioned earlier.

\section{Choosing the final target audience}

We decided to focus on parents of primary school children as our target audience. This would complement the IHC primary school resources [19], with the potential to reinforce learning of both children and their parents, and the potential to reach parents through their children's

Table 4 Journalists' reasons for and against using radio

\begin{tabular}{ll}
\hline In favour of using radio & Against using radio \\
\hline 1. Easily accessible to a large section & 1. Audience's perceived difficulty to tune in to a show consistently at the time a programme is aired \\
of the public & 2. Lack of options to pause or replay the radio programmes at will. \\
2. Free of charge to access & 3. Unstable access to electricity in some areas \\
3. Can be entertaining & 4. The large volume of competing information on radio. \\
4. Allows flexible use of local & 5. The need to use multiple languages. \\
languages & 6. It would be very challenging to get the right people to answer questions as experts on live radio talk \\
& shows as health professionals are usually very busy. \\
& 7. It is difficult to achieve consistent messaging when running live talk shows
\end{tabular}


Table 5 Feedback on early prototypes (rapid response service and news wire service)

\begin{tabular}{|c|c|}
\hline Main theme & Specific feedback \\
\hline Focus on audio messaging & $\begin{array}{l}\text { - Focus on audio messages through radio, as this is the most accessible means of mass communication. } \\
\text { - Make stories available for listening and download online (e.g. via Facebook, YouTube, Sound Cloud, a } \\
\text { project website and iTunes. } \\
\text { - Consider a series of features prepared for specific media (e.g. regional radio) rather than a news service. }\end{array}$ \\
\hline Narrow down the target audience & $\begin{array}{l}\text { - Segment the resources for specific target audiences as it is difficult to develop a single product that } \\
\text { appeals to all. }\end{array}$ \\
\hline Make the aim and content clearer & $\begin{array}{l}\text { - Make it clearer to the audience that we are empowering them to assess claims about the effects of } \\
\text { treatments, not assessing the claims for them. } \\
\text { - Provide a clear message regarding the trustworthiness of each claim. } \\
\text { - Consider using more than one example in the explanations and use claims that are of interest to the target } \\
\text { audience. } \\
\text { - Repeat important information in each story. } \\
\text { - Consider a checklist or a list of reminders for our audience as a quick reference tool. } \\
\text { - Use more than one language. }\end{array}$ \\
\hline $\begin{array}{l}\text { Ensure credibility of the project, } \\
\text { content and sender }\end{array}$ & $\begin{array}{l}\text { - Ensure the audience knows that there is a credible organisation behind the project. } \\
\text { - Provide more information about the claims and their origins to avoid the audience thinking that we are } \\
\text { making the claims. } \\
\text { - Ensure that the editors, producers and other "gatekeepers" understand what the project is about. }\end{array}$ \\
\hline Additional considerations: & $\begin{array}{l}\text { - Train journalists and editors. } \\
\text { - Include fact-checking packages with stories. } \\
\text { - Promote the project and stories ahead of time in various media. }\end{array}$ \\
\hline
\end{tabular}

schools [27]. The checklist could help clarify that the focus of the podcast was on the IHC key concepts, provide a quick reference and help them to remember the concepts.

Having parents as our target audience enabled us to tailor the podcast to a greater extent, focusing on claims, concepts and stories that would be relevant to this audience. We decided to limit the number of episodes for practical reasons (limited time and resources to produce and evaluate them), but also because we thought that parents might not want to listen to a large number of episodes and we did not want to overwhelm them with too much information. We therefore prioritised nine key concepts using the following procedure: each member of our research team independently made a list of the key concepts they thought we should prioritise for the podcast; we summarised our judgements and discussed disagreements until we arrived at a consensus (Table 8).

\section{Version 2: the IHC podcast}

We created a series of eight main episodes, each including a skit in which a claim is made by a character and its trustworthiness is assessed and discussed by other characters. The setting and characters were chosen according to the claim. For example, one episode about the effects of birth control pills was situated at a village health meeting and involved a woman asking a community health worker about the trustworthiness of the claim that birth control pills cause women to gain weight. The skit included an explanation by another character (the community health worker) of why the claim was not trustworthy, by applying an IHC key concept. We used an analogy to help explain the concept, and there was a conclusion with a take-home message. Each main episode was 5-7 min long.

In addition, we developed an introductory episode, 1min recap episode for every two main episodes, and a conclusion episode, making a total of 13 audio files for each of the two commonly spoken languages (English and Luganda). The recap at the end served as a conclusion, repeating the key messages from all the main episodes. During the user testing, participants listened to the episodes one at a time in their preferred language, and they provided feedback in the same language. Table 6 summarises the contents of each episode, the rationale for the choice of claims and the key concept applied in assessing the trustworthiness of the claim. The complete Version 2 of the IHC podcast can be found here (https://www.youtube.com/playlist?list= PLeMvL6ApG1N35f6DQ3qP9fWE7pMEDZTbH).

Findings from user testing are summarised in Additional file 3. Based on these findings, we clarified that the aim of the podcast was to enable people to make choices, not to tell them what to do. We used the metaphor "give a man a fish and you will feed him for a day; teach a man how to fish and you will feed him for a lifetime" in the introduction episode. In addition, we added a short sentence to the introduction for each episode about the difference between telling them whether a claim is right or wrong and teaching them how to assess any claim. We also edited the introduction to each episode to make them shorter, added voice variations and intonations in those that sounded boring and introduced the claim used in each episode in the introduction to the episode.

Main changes to version 2 of the intervention (the IHC Podcast) 
Table 6 Claims used in main episodes of IHC Podcast versions 2 and 3

\begin{tabular}{ll}
\hline Episode and main lesson/key concept & $\begin{array}{l}\text { Claim used in the episode and issues of } \\
\text { concern or subject for discussion }\end{array}$ \\
\hline $\begin{array}{l}\text { Episode 1 } \\
\text { Most treatments have both good and bad } \\
\text { effects (benefits and harms) }\end{array}$ & $\begin{array}{l}\text { "There are herbal medicines that cure mat do not have any bad effects." } \\
\text { and do }\end{array}$ \\
$\begin{array}{l}\text { Episode 2 } \\
\text { Knowledge about the effects of treatments }\end{array}$ & "Zmapp, a new investigational drug in \\
\end{tabular}

The issues or subject for discussion about the claim and reason for inclusion

The claim that herbal treatments do not have any bad effects is untrustworthy since most treatments can have both good and bad effects. How sure can one be that herbal treatments are indeed without any bad effects?

Zmapp was an investigational drug at the time. Evaluation of Zmapp was not yet complete at the time of production but it was given to some health workers who subsequently improved. Given the information available at the time, how sure could we be that Zmapp cures Ebola Virus Disease?

"Eating quail eggs can make one very strong."* There was no known evaluation at the time comparing taking quail eggs to taking nothing or to anything else, to establish if eating the quail eggs makes one stronger. How sure can one be that eating quail eggs will make one stronger in the absence of any fair evaluation of their effects?

Episode 3

"Putting cooking oil on a burn will heal it since Personal experiences are not a reliable basis for it has worked for someone else before" claims about treatment effects

Episode 4

An effect on an outcome may be associated with a treatment, but it may not be the treatment causing the effect to happen

"A lot of women gain weight when they take contraceptive pills."

The claim was based on someone's personal experience using cooking oil on burns wounds. How reliable are personal stories (anecdotes) at predicting how treatments will work?

This claim was based on the association between women using contraceptives and adding weight. Is it possible that an effect on an outcome could be associated with a treatment when it is not the treatment causing the effect?

"An herbal treatment called 'kyogero' stops babies from getting infections because many How long a treatment has been used or how many people have used it is not a reliable basis people have used it for a long time." for judging the effects of treatments.

Episode 6

Opinions of experts can be misleading if they are not based on reliable evidence

According to one expert, "taking some hot pepper will heal stomach ulcers".

Episode 7

Comparisons of treatments should be fair

"Medical male circumcision reduces the chances of acquiring HIV."

*"Group support treatment is helpful for someone who has depression and HIV because the treatment has been compared with other alternatives and found to be effective."

According to findings from a small study: "washing hands with soap does not stop

Episode 8

Single comparisons of treatments or comparisons with very few people can be misleading
This claim is based on the finding that many people have used the herbal treatment for a long time. Does the finding that many people have used a treatment for a long time mean that the treatment is effective and/or safe?

The claim was based simply on what an expert said- an expert opinion. Is it possible that experts can be wrong in their opinions, for example, if they are not based on the best evidence?

This claim was based on a fair comparison of medical male circumcision to prevent HIV and no circumcision. What are fair comparisons? Do fair comparisons of treatments offer a reliable basis for determining if treatments are effective and/or safe?

This claim was based on a fair comparison of using group support treatment and not using it for people with depression. What are fair comparisons? Do fair comparisons of treatments offer a reliable basis for determining if treatments are effective and/or safe?

The claim was based on a single study with very few participants. To what extent can we rely on single studies with very few participants?

*Claims used in version 3 of the IHC podcast in place of the one used in version 2

${ }^{\S} \mathrm{A}$ complete description of the IHC Key concept and their implications can be found in Austvoll-Dahlgren et al. [30] 
- Ensuring that men and women were fairly represented in the characters for each episode and that the story and content of each episode would appeal to both men and women

- Adding more interactive dialogue and distributing talking time more evenly across the characters

- Correcting all intonations where voices were experienced as flat and ensuring that actors spoke slowly enough for listeners to comprehend

- Having the characters who learn something in each episode express wanting to share it with others

- Having a theme song (in both Luganda and English)

- Replacing the claims used in some of the episodes

- Clarifying or adding relevant information about the specific claims that were used, such as adding other examples of artemisinin combination treatment (ACT) to episode 1 and adding a message about what you should do when you get a burn to episode 3

- Improving the explanation of how and why health researchers sometimes compare using a treatment to "no treatment" or to "doing nothing"

- Improving the explanation of the concept that association is not the same as causation in episode 4

- Making specific changes to some of the episodes, such as adding restaurant background sounds to episode 3 and changing the setting of episode 4

- Adding more information to the conclusion episode, including more details from each episode

- Removing terms that appear for the first time in the conclusion episode

Table 7 The Health Choices radio programme

The Health Choices radio programme featured a radio show host who interviewed a health researcher and a professor about two treatment claims. For each claim, people from the target audience gave their opinions before and after the trustworthiness of the claim was discussed by the three show participants.

To explain the trustworthiness of each claim, the guests (health researcher and professor) applied an $\mathrm{IHC}$ key concept to assess the claim and used an analogy to help explain that concept. Then, the best available evidence from a systematic review was presented and used to assess the trustworthiness of the claim. More information was provided about where a listener could access research evidence pertaining to similar claims. Key take-home messages were about how to assess the trustworthiness of treatment claims. We produced two prototypes, both of which can be found here (https://www.youtube.com/playlist?list=PLeMvL6ApG1N2G_aT-nfOI1NAOyF9FzKjb). Each episode had the following:

1. Welcome remarks for the programme and the episode

2. A recap of the previous episode

3. An overview of the episode

4. A skit introducing the first claim

5. Opinions from three people from the target audience about the first claim before listening to an explanation

6. Explanation of the reliability of the first claim applying an IHC key concept

7. A presentation of the findings of a systematic review

8. Opinions from the same three people about the claim after listening

to the explanation and evidence

9. Introduction of the second claim and a repetition of steps 5 to 8

10. Conclusion of the episode
Table 8 Nine key concepts prioritised for the Informed Health Choices podcast

Recognising an unreliable basis for treatment claims

- Treatments may be harmful

- Personal experiences or anecdotes (stories) are an unreliable basis for assessing the effects of most treatments

- An "outcome" may be associated with a treatment but not caused by the treatment

- Widely used treatments or treatments that have been used for a long time are not necessarily beneficial or safe

- Opinions of experts or authorities do not alone provide a reliable basis

for deciding on the benefits and harms of treatments

Understanding whether comparisons are fair and reliable

- Identifying effects of treatments depends on making comparisons

- Apart from the treatments being compared, the comparison groups

need to be similar (i.e. "like needs to be compared with like")

- The results of single comparisons of treatments can be misleading

Making informed choices about treatments

- Decisions about treatments should not be based on considering only their benefits

\section{Version 3: the final IHC podcast}

In addition to the changes above, we removed the credits to partner institutions in countries other than Uganda from the introduction of each episode. We did this to avoid giving the impression that the messages were coming from a "foreign" place. We emphasised more clearly the difference between this programme and other programmes in every episode by including the statement "In many health programmes people tell you what health choices to make: but in this programme, we explain why some of the things people say about treatments are trustworthy and others are not. If you understand this you can choose for yourself what treatments are right for you".

To further focus attention on the lessons about assessing claims in each episode, we decided to add a key concept to the introduction of each episode: most treatments of any kind have benefits and harms. Based on our observations of very strong pre-existing beliefs about some claims, we felt that including this key concept in the introduction of each episode would help the audience pay attention to the explanations. We changed the introduction of each episode to include the statement: "most treatments of any type have good effects and bad effects".

The final podcast can be found here (https:// www.informedhealthchoices.org/podcast-for-parents/). It is a series of 13 audio messages teaching nine key concepts that people need to understand and apply in order to assess the trustworthiness of claims about treatments and make informed health choices. This includes an introductory episode, 8 main episodes, 3 recaps to the episodes and a conclusion episode, each produced in two languages. Each main episode lasts 5-7 min, and each recap lasts $1-3 \mathrm{~min}$. The theme song has a mixture of Luganda and English in "Afrobeat", a 
popular music genre in Uganda. We incorporated parts of the song at the beginning, in the background and at the end of each episode.

With the help of research assistants and members of our target audience, we explored the feasibility of using small portable media players to deliver the podcast to parents. At the time of development, content such as ours would be challenging to access through internet-based technologies and smartphone access was still very low.

We found that preloading the audio messages onto small inexpensive portable media players and giving these to the parents was a feasible way to deliver the IHC podcast. This also enabled us to circumvent additional problems associated with radio described above. The parents were pleased that they had the opportunity and sufficient time to replay the episodes any time they wished and that the messages on the devices could be shared with others.

\section{Discussion}

We discuss our findings in relation to each of the facets of the honeycomb framework of user-experience [20], focusing on lessons that might be relevant to other researchers working in this and related fields.

\section{Usefulness}

We found increasing appreciation of the usefulness of this work as participants began to understand how much of the "health advice" to which they were exposed was in fact unsubstantiated claims about what we should do to maintain or improve our health. We were informed repeatedly by some editors that if someone can pay for the media space it does not matter what they have to say as long as it is not "politically offensive" or "destructive" to their media enterprise. "It is not our duty to check the trustworthiness of the messages in advertisements". Most of the people with whom we interacted mistakenly assumed that the government approved all health-related content in the media. People and companies continue to make unsubstantiated claims about the effects of treatments in the mainstream media. Overall, the IHC podcast was seen as a useful tool that could help empower people to question more and assess statements made about the effects of treatments, both in the mass media and elsewhere.

\section{Usability and understandability}

In the early stages of development, we encountered many usability challenges. For example, the print version of the structured press releases lacked important content and the writing style was not acceptable to media houses. The audio version had confusing content, difficult medical terminology, insufficient explanations and a host of production glitches.
People often did not understand the main purpose of the project, and this in turn led to misunderstandings about the content, such as thinking we were going to provide them with health advice. There may be several reasons for this. One is that a lot of people do not routinely question the trustworthiness of treatment claims. When they do, they frequently consider who is making the claim, rather than the basis of the claim. Although fact-checking is common, critically appraising claims about treatment effects is uncommon and is seldom done in a systematic way in the mass media [1, 5, 7-11]. People also question the ability of journalists and nonacademic members of the public to assess the trustworthiness of treatment claims and assume that this is something that requires professional training. We worked with our audiences to adjust each episode, and the approach to the podcast as a whole until they were satisfied that the content was understandable and the podcast was usable.

\section{Credibility}

A few participants in the user testing questioned who was funding this work and who our partners were. Otherwise, we did not find creditability to be a major problem. This may be, in part, because the project was based at Makerere University, which is well known in Uganda. Some journalists, however, did question the source of funding for the project. Concern about funders pushing specific agendas is common in Uganda. We were open about funding sources and the roles of the funders in the project, which helped reassure the journalists. However, we removed credits to non-Ugandan partners in the audio recording so that it would not interfere with the credibility. This information was available for anyone who visited the web site for more details.

\section{Desirability}

Early users (journalists and editors) did not experience most of our initial ideas as desirable (i.e. the structured press releases, the "Be Fair and Compare" news service for journalists and the first version of the Health Choices programme), largely because they perceived these ideas as very unfamiliar and foreign. We abandoned several ideas for this reason.

We changed our target audience, focusing on reaching the public directly, rather than through journalists and editors, and narrowing our target audience to parents of primary school children. We also changed to a storytelling approach to introduce the claims and explain their trustworthiness in version 2 of the IHC podcast, because people tend to make sense of their lives through stories, they hear in the contexts with which they are familiar. A systematic review of the effect of changing healthpromoting behaviours through narrative interventions 
supports the use of a narrative approach [46]. Characters in the narrative can model new behaviours and enhance self-efficacy [47]. Some participants demonstrated the desirability of the podcast by asking if they could have all the episodes so they could listen to them at once or listen more in their own time. A health communication NGO and producers at the Uganda Broadcasting Corporation expressed interest in airing the podcast on radio as part of their health communication programming.

\section{Identification}

Recording in Luganda was likely the most important strategy we employed to create a product that did not feel alienating and foreign to our participants, most of whom had Luganda as their first language and were not fluent in English. We also used terminology, examples of claims, stories and music genres that were appropriate for our target audience. In the earlier versions of the media resources, participants felt that we used unfamiliar language, which alienated them and appeared to reduce their motivation to engage with the content. In one episode, we used a claim which we mentioned was from research done in the Democratic Republic of Congo on the effect of handwashing with soap on reducing diarrhoea. Whereas handwashing is a hygienic practice applicable to Uganda and the whole world, some users experienced the use of an example of a study from Congo as foreign. We also used a claim about Zmapp, which was used to treat American aid workers during the Ebola crisis in western Africa. Again, in addition to Zmapp being a difficult word, the story of Ebola in West Africa was not something with which they could easily identify. We initially used a jazz jingle that people felt was "music for the elite". We changed that to "Afrobeat", a music genre most Ugandans listen to.

\section{Reflexivity}

Our own interest was to develop and test our intervention in collaboration with the members of our target audience. We do not know to what extent this might have presented biases in our assessments; however, it is possible that because of project deadlines we might not have explored all the end-users' feedback to the extent that it might have required. Although we intentionally looked for both negative and positive feedback, our desire to develop useful resources might have led us to interpret some of the feedback more positively or more negatively. Again, we do not know the extent to which this might have been a problem, if at all. Our own positions as researchers from reputable organisations that are well known by the community might have introduced biases in our end-users' responses, perhaps this might have led them to provide more positive feedback about the resources.

\section{Conclusions}

We have developed an educational podcast to help parents assess the trustworthiness of claims about the effects of treatments. During the design process, we encountered many problems with the early prototypes. We were able to address those problems by working directly with end-users through an iterative, humancentred design approach, which engages end-users in the design process and can help to ensure that an intervention is relevant and acceptable [48]. As a result, we were able to design an educational podcast that listeners experienced as useful, understandable, credible, desirable and appropriate. This, in turn, helped to ensure that our intervention was effective [44]. To our knowledge, the effectiveness of other podcasts for non-formal education or health education have not been evaluated in randomised trials [49-54], and we are unaware of other work describing the use of a similar process to design a mass media intervention to enable people to think more critically about treatment claims.

Because we tailored the podcast to our target audience, it is less likely it will feel familiar to people in other countries. Therefore, the IHC podcast that we developed is unlikely to be transferable to many other contexts. However, others can use the same approach to create a podcast tailored to their target audience, using a guide we have prepared for this purpose [55].

\section{Supplementary information}

Supplementary information accompanies this paper at https://doi.org/10. 1186/s40814-019-0540-4

Additional file 1. Idea generation and selection

Additional file 2. Structured press releases and a news service

Additional file 3. Findings from user testing the $\mathrm{IHC}$ podcast

\section{Abbreviation}

IHC: Informed Health Choices

\section{Acknowledgements}

We are grateful to the Global Health and Vaccination Research (GLOBVAC) programme of the Research Council of Norway for the research grant that supported this work and to the National Institute for Health Research for supporting lain Chalmers and the James Lind Initiative. We would like to thank Sir lain Chalmers for his advice and support throughout the development process. We are also grateful to the DELTAS Africa Initiative for their support to NKS and DS through grant \# DEL-15-011 to THRiVE-2. We are very grateful to all the journalists, editors, actors, musicians and producers who helped with the development of mass media resources and the Informed Health Choices theme song, especially Christopher Kiwanuka, Abraham Jjuko and Swangz Avenue.

We would like to acknowledge Margaret Nabatanzi, Martin Mutyaba and Esther Nakyejwe, who were the chief data managers, for their immeasurable help with the data collection and management on the IHC project. We would also like to thank the Informed Health Choices National Advisory Panel and our journalist network for the support, feedback and advice they 
provided. Finally, we are especially grateful to all the parents and other endusers who provided ideas and feedback for the development, user testing and piloting of the Informed Health Choices mass media resources.

\section{Authors' contributions}

DS, AN, SR and ADO drafted this article manuscript. All the authors reviewed the manuscript, provided input and agreed on this final version. DS and AN were the principal investigators, supervised by ADO, NKS and AF and supported by other investigators. DS, AN and ADO wrote the lyrics of the IHC theme song to which other investigators provided feedback. MO drafted the scripts for the episodes. DS and ADO reviewed them, and all investigators provided input. DS translated the scripts to Luganda. All the investigators participated in the analyses of findings for each iterative cycle and agreed on how to use the findings for the next cycle in the development process. DS is a medical doctor with over 5 years research experience and AN is a social scientist.

\section{Funding}

This study was funded by the Norwegian Research Council, as part of the Supporting Informed Health Choices in Low-Income Countries project (grant number 220603/H10), to the Norwegian Institute of Public Health.

\section{Availability of data and materials}

All data generated or analysed during this study are included in this published article and its supplementary information files. Any additional raw data will be available from the corresponding author on reasonable request.

\section{Ethics approval and consent to participate}

The study was approved by Makerere University School of Medicine Research and Ethics Committee and the Uganda National Council of Science and Technology as part of the Supporting Informed Healthcare Choices in Low-income Countries Project in August 2013 and renewals were obtained for each project year.

All potential participants were asked for and provided written consent before participating in the study. All participant information was kept confidential and participants could not be identified from the information they provided. We asked participants for additional consent if we intended to use their pictures, video or audio recordings in the development of the media resources or in presentations and publications

\section{Consent for publication}

Consent to publish was obtained at the beginning of the study together with consent to participate described above.

\section{Competing interests}

The authors declare that they have no competing interests.

\section{Author details}

${ }^{1}$ College of Health Sciences, Makerere University, Kampala, Uganda. ${ }^{2}$ University of Oslo, Oslo, Norway. ${ }^{3}$ Centre for Informed Health Choices, Norwegian Institute of Public Health, Postboks 222 Skøyen, 0213 Oslo, Norway. ${ }^{4}$ Health Systems Research Unit, South African Medical Research Council, Cape Town, South Africa. ${ }^{5}$ Great Lakes University of Kisumu, Kisumu, Kenya. ${ }^{6}$ Infodesignlab, Oslo, Norway.

Received: 21 July 2019 Accepted: 2 December 2019 Published online: 29 December 2019

\section{References}

1. Walsh-Childers K, Braddock J, Rabaza C, Schwitzer G. One step forward, one step back: changes in news coverage of medical interventions. Health Commun. 2016;16:1-14.

2. Sumner P, Vivian-Griffiths S, Boivin J, Williams A, Bott L, Adams R, et al. Exaggerations and caveats in press releases and health-related science news. PLoS One. 2016;11:e0168217.

3. Johansen L, Bjørndal A, Flottorp S, Grøttling T, Oxman A. Evaluation of health information in newspapers and brochures. What can we believe? Tidsskr Nor Laegeforen. 1996;116:260-4.

4. Wang MTM, Grey A, Bolland MJ. Conflicts of interest and expertise of independent commenters in news stories about medical research. CMAJ. 2017;189:E553-9.
5. Schwartz LM, Woloshin S, Andrews A, Stukel TA. Influence of medical journal press releases on the quality of associated newspaper coverage: retrospective cohort study. BMJ. 2012;344:d8164.

6. Lewis $M$, Orrock $P$, Myers $S$. Uncritical reverence in $C M$ reporting: assessing the scientific quality of Australian news media reports. Heal Sociol Rev. 2010;19:57-72.

7. de Oliveira MS, Paiva LHC, Costa JV, Pinto-Neto AM. Women's health in the Brazillian press: analysis of scientific quality in weekly magazines. Interface (Botucatu). 2009;13:7-16.

8. Schwitzer G. How do US journalists cover treatments, tests, products, and procedures? An evaluation of 500 stories. PLoS Med. 2008;5:e95.

9. Claire G, Elizabeth P, Oxman AD. Portals to Wonderland: health portals lead confusing information about the effects of health care. BMC Med Inform Decis Mak. 2005;5:7.

10. Biondo $E$, Khoury M. Validation of a questionnaire to assess the quality of health information in Argentinian newspapers. Biomédica. 2005;25:366-76.

11. Moynihan R, Bero L, Ross-Degnan D, Henry D, Lee K, Watkins J, et al. Coverage by the news media of the benefits and risks of medications. $\mathrm{N}$ Engl J Med. 2000;342:1645-50.

12. Bala MM, Strzeszynski L, Topor-Madry R. Mass media interventions for smoking cessation in adults. Cochrane Database Syst Rev. Chichester: Wiley; 2017.

13. Vidanapathirana J, Abramson MJ, Forbes A, Fairley C. Mass media interventions for promoting HIV testing. Cochrane Database Syst Rev. 2005;3:CD004775.

14. Grilli R, Ramsay C, Minozzi S. Mass media interventions: effects on health services utilisation. Cochrane Database Syst Rev. Chichester: Wiley; 2002.

15. Berkman ND, Sheridan SL, Donahue KE, Halpern DJ, Viera A, Crotty K, et al. Health literacy interventions and outcomes: an updated systematic review. Evid Rep Technol Assess (Full. Rep). 2011;155:1-941.

16. Eichler K, Wieser S, Brügger U. The costs of limited health literacy: a systematic review. Int J Public Health. 2009;54:313.

17. Johnson SB, Park HS, Gross CP, Yu JB. Complementary medicine, refusal of conventional Cancer therapy, and survival among patients with curable cancers. JAMA Oncol. 2018;4:1375-81.

18. Gallagher J. Tamiflu: millions wasted on flu drug, claims major report. BBC News. 2014. Available online at https://www.bbc.com/news/health-269544 82. Accessed 8 June 2019

19. Boseley S. Scientists say UK wasted $£ 560 \mathrm{~m}$ on flu drugs that are not proven. Guard. 2014.

20. Lynch J, Smith GD, Harper S, Hillemeier M, Ross N, Kaplan GA, et al. Is income inequality a determinant of population health? Part 1. A systematic review. Milbank Q. 2004;82:5-99.

21. Lynch J, Smith GD, Harper S, Hillemeier M. Is income inequality a determinant of population health? Part 2. U.S. National and Regional Trends in income inequality and age- and cause-specific mortality. Milbank Q. 2004;82:355-400.

22. WHO (World Health Organisation). 10 facts on health inequities and their causes. 2017. Available from: https://www.who.int/features/factfiles/health_ inequities/en/. Cited 2019 Nov 15.

23. Chetty R, Stepner M, Abraham S, Lin S, Scuderi B, Turner N, et al. The association between income and life expectancy in the United States, 2001 2014. JAMA - J Am Med Assoc. 2016;315:1750-66.

24. Cutler D, Deaton A, Lleras-Muney A. The determinants of mortality. J Econ Perspect. 2006;20:97-120.

25. The Informed Health Choices Group. Supporting informed healthcare choices in low-income countries - final report. IHC Update 9 January 2018. 2018.

26. Van Deurzen I, Van Oorschot W, Van Ingen E. The link between inequality and population health in low and middle income countries: policy myth or social reality? PLoS One. 2014;9:e115109.

27. Messias E. Income inequality, illiteracy rate, and life expectancy in Brazil. Am J Public Health. 2003;93:1294-6.

28. Hosseinpoor AR, Bergen N, Kunst A, Harper S, Guthold R, Rekve D, et al. Socioeconomic inequalities in risk factors for non communicable diseases in low-income and middle-income countries: results from the world health survey. BMC Public Health. 2012;12:912.

29. Karlsson M, Nilsson T, Lyttkens $\mathrm{CH}$, Leeson $\mathrm{G}$. Income inequality and health: importance of a cross-country perspective. Soc Sci Med. 2010;70:875-85.

30. Austvoll-Dahlgren A, Oxman AD, Chalmers I, Nsangi A, Glenton C, Lewin S, et al. Key concepts that people need to understand to assess claims about treatment effects. J Evid Based Med. 2015;8:112-25.

31. Semakula D, Nsangi A, Oxman AD, Sewankambo NK. Priority setting for resources to improve the understanding of information about claims of treatment effects in the mass media. J Evid Based Med. 2015;8:84-90. 
32. Chalmers I, Oxman AD, Austvoll-Dahlgren A, Ryan-Vig S, Pannell S, Sewankambo N, et al. Key concepts for informed health choices: a framework for helping people learn how to assess treatment claims and make informed choices. BMJ Evidence-Based Med. 2018:23:29-33.

33. Nsangi A, Semakula D, Rosenbaum S. Development of the informed health choices resources to teach primary school children to assess claims about treatment effects in four countries. IHC Work. Pap; 2017.

34. DAM R, Siang T. 5 Stages in the Design Thinking Process. 2019. Available from: https://www.interaction-design.org/literature/article/5-stages-in-thedesign-thinking-process. Cited 2019 Nov 12.

35. Rosenbaum SE. Improving the user experience of evidence: a design approach to evidence-informed health care. Arkitektur- og designhøgskolen i Oslo; 2011.

36. IDEO. Human centered design toolkit. 1st ed. San Francisco: IDEO; 2011.

37. Sanders BNE, Stappers PJ. Co-creation and the new landscapes of design. Co-design Int J CoCreation Des Arts. 2008:4:5-18.

38. Giacomin J. What is human centred design? Des J. 2014;17:606-23.

39. Uganda Bureau of Statistcs (UBOS) and ICF. Uganda Demographic and Health Survey 2016: key indicators report. Kampala, and Rockville: UBOS and ICF; 2017.

40. Austvoll-Dahlgren A, Nsangi A, Semakula D. Interventions and assessment tools addressing key concepts people need to know to appraise claims about treatment effects: a systematic mapping review. Syst Rev. 2016;5:215.

41. Castle JC, Chalmers I, Atkinson P, Badenoch D, Oxman AD, AustvollDahlgren $A$, et al. Establishing a library of resources to help people understand key concepts in assessing treatment claims - the "critical thinking and appraisal resource library" (CARL). PLoS One. 2017;12: e0178666.

42. Hillstrom K, Hillstrom L. EditorsBrainstorming. Encycl. Small Bus. Farmington Hills: Gale Cengage; 2002.

43. Bergstrom JR. Moderating Usability Tests; 2013.

44. Semakula D, Nsangi A, Oxman AD, Oxman M, Austvoll-Dahlgren A, Rosenbaum S, et al. Effects of the informed health choices podcast on the ability of parents of primary school children in Uganda to assess claims about treatment effects: a randomised controlled trial. Lancet Elsevier. 2017; 390:389-98.

45. Larsson A, Oxman AD, Carling C, Herrin J. Medical messages in the media-barriers and solutions to improving medical journalism. Heal Expect. 2003;6: 323-31 2004/03/26.

46. Perrier M-J, Ginis KAM. Changing health-promoting behaviours through narrative interventions: a systematic review. J Health Psychol. SAGE Publications Ltd. 2016. https://doi.org/10.1177/1359105316656243.

47. Bandura A. Self efficacy: toward a unifying theory of behaviour change. Psychol Rev. 1977;84:191-215.

48. Kushniruk A, Nohr C. Participatory design, user involvement and health IT evaluation. Stud Heal Technol Inform Evid Based Heal Inform. 2016;222:139-51.

49. Hew KF. Use of audio podcast in K-12 and higher education: a review of research topics and methodologies. Educ Technol Res Dev. 2009;57:333-57.

50. Crompton H, Burke D, Gregory K, Gräbe C. The use of mobile learning in science: a systematic review. J Sci Educ Technol. 2016;25:149-60.

51. Higgins $S$, Katsipataki M. Evidence from meta-analysis about parental involvement in education which supports their children's learning. J Child Serv Emerald. 2015;10:280-90.

52. Jacobs RJ, Lou JQ, Ownby RL, Caballero J. A systematic review of eHealth interventions to improve health literacy. Health Informatics J. 2016;22:81-98.

53. Sondaal SFV, Browne JL, Amoakoh-Coleman M, Borgstein A, Miltenburg AS, Verwijs $M$, et al. Assessing the effect of mHealth interventions in improving maternal and neonatal care in low- and middle-income countries: a systematic review. PLoS One. 2016;11:e0154664.

54. Annaim A, Lassiter M, Viera AJ, Ferris M. Interactive media for parental education on managing children chronic condition: a systematic review of the literature. BMC Pediatr. 2015;15:201.

55. The Informed Health Choices Group. Guide for translating and adapting the Informed Health Choices (IHC) podcast. Informed Health Choices Working Paper. Oslo; 2017. Available from: http://www.informedhealthchoices.org/ wp-content/uploads/2016/08/GUIDE-for-translating-and-adapting-the-IHCPodcast.pdf. Cited 2018 Apr 15

\section{Publisher's Note}

Springer Nature remains neutral with regard to jurisdictional claims in published maps and institutional affiliations.

\section{Ready to submit your research? Choose BMC and benefit from:}

- fast, convenient online submission

- thorough peer review by experienced researchers in your field

- rapid publication on acceptance

- support for research data, including large and complex data types

- gold Open Access which fosters wider collaboration and increased citations

- maximum visibility for your research: over $100 \mathrm{M}$ website views per year

At BMC, research is always in progress.

Learn more biomedcentral.com/submissions 